\title{
Complete rescue of obesity, diabetes, and infertility in $d b / d b$ mice by neuron-specific LEPR-B transgenes
}

\author{
Carl de Luca, ${ }^{1}$ Timothy J. Kowalski, ${ }^{2}$ Yiying Zhang, ${ }^{3}$ Joel K. Elmquist, ${ }^{4}$ Charlotte Lee, ${ }^{4}$ \\ Manfred W. Kilimann, ${ }^{5}$ Thomas Ludwig, ${ }^{6}$ Shun-Mei Liu, ${ }^{7}$ and Streamson C. Chua Jr. ${ }^{7}$
}

1Department of Medicine, Division of Preventative Medicine, Columbia University, New York, New York, USA.

2Department of Cardiovascular Branch/Endocrinology Biological Research, Central Nervous System/Cardiovascular Branch Pharmacology,

Schering-Plough Research Institute, Kenilworth, New Jersey, USA. ${ }^{3}$ Department of Pediatrics, Division of Molecular Genetics, Columbia University, New York, New York, USA. 'Department of Medicine, Division of Endocrinology, Beth Israel Deaconess Medical Center, Harvard Medical School, Boston,

Massachusetts, USA. 5Department of Cell and Molecular Biology, Uppsala Universitet, Uppsala, Sweden. ${ }^{6}$ Department of Anatomy and Cell Biology,

Columbia University, New York, New York, USA. Departments of Medicine and Neuroscience, Albert Einstein College of Medicine, New York, New York, USA.

\begin{abstract}
We have generated mice that carry a neuron-specific leptin receptor (LEPR) transgene whose expression is driven by the rat synapsin I promoter synapsin-LEPR B (SYN-LEPR-B). We have also generated mice that are compound hemizygotes for the transgenes SYN-LEPR-B and neuron-specific enolase-LEPR B (NSE-LEPR-B). We observed a degree of correction in $d b / d b$ mice that are hemizygous (Syn $d b / d b)$ and homozygous (Syn/Syn $d b / d b)$ for the SYN-LEPR-B transgene similar to that previously reported for the NSE-LEPR-B transgene. We also show complete correction of the obesity and related phenotypes of $d b / d b$ mice that are hemizygous for both NSE-LEPR-B and SYN-LEPR-B transgenes $(N s e+S y n d b / d b)$. Body composition, insulin sensitivity, and cold tolerance were completely normalized in $N s e+S y n d b / d b$ mice at 12 weeks of age compared with lean controls. In situ hybridization for LEPR B isoform expression in Nse+Syn $d b / d b$ mice showed robust expression in the energy homeostasis-relevant regions of the hypothalamus. Expression of 3 neuropeptide genes, agouti-related peptide (Agrp), neuropeptide $Y(N p y)$, and proopiomelanocortin (Pomc), was fully normalized in dual transgenic $d b / d b$ mice. The 2 transgenes in concert conferred normal fertility to male and female $d b / d b$ mice. Male mice with partial peripheral deletion of $L e p r$, induced in the periweaning phase, did not show alterations in body composition or mass. In summary, we show that brain-specific leptin signaling is sufficient to reverse the obesity, diabetes, and infertility of $d b / d b$ mice.
\end{abstract}

\section{Introduction}

Leptin, the adipocyte-derived hormone, serves as an indicator of stored energy in the form of white adipose tissue, (1) and circulating concentrations of leptin are positively correlated with adiposity (2). The leptin receptor (LEPR) belongs to the cytokine receptor class I superfamily (3). There are several known isoforms of LEPR in mice due to alternative splicing, and LEPR B isoform (LEPR-B), also known as the long form, is the only STAT3 signaling-competent isoform. Defective leptin signaling due to mutations in the leptin gene, obese $(o b / o b)$, or mutations in the receptor in mice, diabetes $(d b / d b)$, and in rats, fatty $(f a / f a)$, causes a disruption in energy balance resulting in obesity from hyperphagia and decreased energy expenditure $(2,4,5)$. A similar phenotype is observed in humans with mutations in the leptin or the LEPR genes $(6,7)$. These phenotypes are mediated by the

Nonstandard abbreviations used: AGRP, agouti-related peptide; ARC, arcuate nucleus; CART, cocaine amphetamine-regulated transcript; DEXA, dual energy $\mathrm{X}$-ray absorptiometry; DMN, dorsomedial nucleus; HOMA, homeostasis model assessment; Hprt, hypoxanthine guanine phosphoribosyl transferase; LEPR, leptin receptor; LEPR-B, LEPR B isoform; LH, lateral hypothalamus; NPY, neuropeptide Y; NSE-LEPR-B, neuron-specific enolase-LEPR-B; NTS, nucleus of the tractus solitarius; PMN, premammilary nucleus; POMC, proopiomelanocortin; PVN, paraventricular nucleus; 3'-RACE, 3'-rapid amplification of cDNA ends; SYN I, synapsin I; SYN-LEPR-B, synapsin-LEPR-B; Tam, tamoxifen; VMN, ventromedial nucleus. Conflict of interest: The authors have declared that no conflict of interest exists. action of leptin in hypothalamic neurons bearing the B isoform of the LEPR. In the hypothalamus, leptin activates the JAK/STAT pathway in neurons that coexpress $\alpha$-melanocyte stimulating hormone $(\alpha-\mathrm{MSH})$ and cocaine amphetamine-regulated transcript (CART) and represses neurons coexpressing neuropeptide Y (NPY) and agouti-related peptide (AGRP). While these arcuate nucleus neurons are known to be important mediators of leptin action, the full set of leptin-sensitive neurons remains to be fully elucidated. Ultimately, leptin signaling results in a decrease in feeding and an increase in energy expenditure in order to maintain energy homeostasis. In states of negative energy balance such as starvation, a decrease in leptin levels causes an increase in food intake and a decrease in energy expenditure by derepressing NPY/AGRP expression and decreasing activity of proopiomelanocortin/CART (POMC/CART) neurons (8).

We have previously reported the effects of the neuron-specific enolase-LEPR B (NSE-LEPR-B), which is expressed exclusively in the mouse central nervous system due to the neuronal specificity conferred by the positively-regulated ENO2 promoter $(9,10)$. This transgene in the hemizygous state partially ameliorates the obesity and related phenotypes of diabetes $\left(d b^{3 J} / d b^{3 J}\right.$ and $\left.d b / d b\right)$ mice. However, our data demonstrate that the degree of correction conferred by the NSE-LEPR-B transgene is dose dependent and is insufficient to completely normalize $d b / d b$ mice. A possible explanation for the incomplete rescue, even with the increased gene dosage, is that NSE-LEPR-B is not sufficiently 


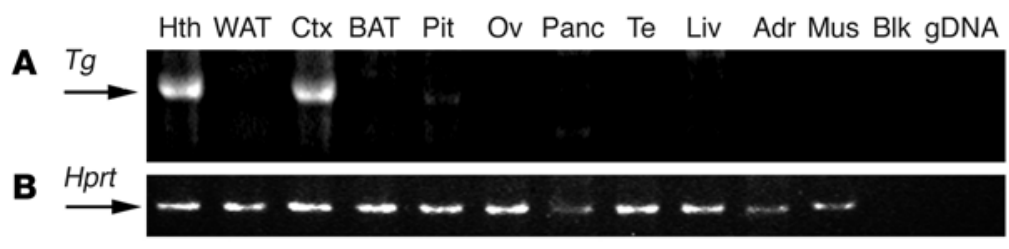

Figure 1

Transgene tissue expression. (A) SYN-LEPR-B transgene expression analysis in several tissues of Syn- $d b 3 \mathrm{~J} / d b 3 \mathrm{~J}$ mice. A bp fragment of approximately 1100 is generated from tissue cDNA when the SYN-LEPR-B transgene is expressed. (B) Expression of Hprt is used as a loading control. Fragments from Hprt generate a 195-bp fragment. Lanes correspond to tissues in A and B. Hth, hypothalamus; WAT, white adipose tissue; Ctx, cerebral cortex; BAT, brown adipose tissue; Pit, pituitary gland; Ov, ovary; Panc, pancreas; Te, testes; Liv, liver; Adr, adrenal gland; Mus, skeletal muscle; Blk, blank. gDNA is used as a control for genomic DNA contamination. of the mice by a negative regulatory mechanism via the neuron-restrictive silencer factor/RE-1 silencing transcription factor (NRSF/REST) binding motif $(14,15)$. The SYN I promoter is regulated differently from the NSE promoter, which may result in spatial differences as well as differences in strength of LEPR-B expression. We report the effect of this transgene on the obesity and diabetes of $d b / d b$ mice in the hemizygous state (Syn $d b / d b)$ and in the homozygous state (Syn/Syn $d b / d b)$. In addition, we crossbred Nse/Nse $d b / d b$ mice with Syn $d b /+$ mice to create compound hemizygous $N s e+S y n d b / d b$ mice to test whether the combination of transgenes with potentially complementary expression patterns is more effective than either transgene alone in preventing the $d b / d b$ phenotype. expressed in all relevant hypothalamic neurons. The incomplete correction of the obese phenotype, even in Nse/Nse $d b / d b$ mice, also leaves the question of whether peripheral leptin signaling is required in addition to neuron-specific leptin signaling to completely normalize $d b / d b$ mice. Recent work regarding peripheral leptin signaling in skeletal muscle has shown it to regulate AMP kinase to reduce intracellular lipid content although it has not been shown to affect body weight in rodents (11). In addition, recent work by Huan et al. suggest that adipocyte-specific reduction of LEPR by antisense RNA causes a significant increase in adiposity in mice due to reduced leptin signaling through LEPR-B (12). However, it is unclear if the increase in adiposity is caused by defective leptin signaling or by the technical knockout experimental approach used. This approach has been shown to cause obesity in mice independently of the antisense RNA target sequence used (13).

In this report, we analyze the effects of a new neuron-specific transgene, synapsin-LEPR-B (SYN-LEPR-B), in $d b / d b$ mice. The SYN-LEPR-B transgene expresses LEPR-B specifically in neurons. The rat synapsin I (SYN I) promoter used in the construction of this transgene restricts expression to the central nervous system

\section{Results}

Expression of SYN-LEPR-B transgene is restricted to brain. We performed nested $3^{\prime}$-rapid amplification of cDNA ends (3'-RACE) to assess the neuronal specificity of SYN-LEPR-B transgene expression. The tissues analyzed were the hypothalamus, cerebral cortex, pituitary gland, liver, pancreas, skeletal muscle, white adipose, brown adipose, adrenal gland, ovary, and testes. We found overall expression of the SYN-LEPR-B transgene was restricted to brain, including very low levels of expression in the pituitary gland and no detectable expression in the other peripheral tissues examined (Figure 1).

We have also determined spatial expression patterns conferred by the SYN-LEPR-B transgene, the NSE-LEPR-B transgene, and both transgenes together in the hypothalamus using in situ hybridization. The use of transgenic $d b 3 \mathrm{~J} / d b 3 \mathrm{~J}$ mouse brains eliminated the signal from the endogenous Lepr gene as the exonic 17-bp deletion in the $d b 3 \mathrm{~J}$ allele greatly attenuates expression. In general, we observed stronger hybridization signal intensity by the SYN I promoter-driven transgene than by the NSE promoter-driven transgene while both showed stronger expression compared with wild type. The most intense hybridization signal intensity was noted in the brain sections from the compound transgenic Nse+Syn

\section{Figure 2}

Transgene expression in the PVN. In situ hybridization of LEPR-B mRNA in hypothalamic brain sections, including the PVN. Counterstained sections are represented in A, C, E, and G, and in situ hybridization autoradiographic images are represented in $\mathbf{B}, \mathbf{D}, \mathbf{F}$, and $\mathbf{H}$. Genotypes are indicated. A and $\mathbf{B}$ represent +/+ mice, $\mathbf{C}$ and $\mathbf{D}$ represent Syn $d b / d b$ mice, $\mathbf{E}$ and $\mathbf{F}$ represent $N s e d b / d b$ mice, and $\mathbf{G}$ and $\mathbf{H}$ represent $N s e+S y n d b / d b$ mice. The NSE-LEPR-B transgene (F) and wild-type LEPR-B (B) are weakly expressed in the PVN when compared with the SYN-LEPR-B transgene (D). The complementation of expression pattern is evident in $(\mathbf{H})$, where both transgenes are coexpressed in Nse+Syn $d b / d b$ mice. Magnification, $\times 20$.
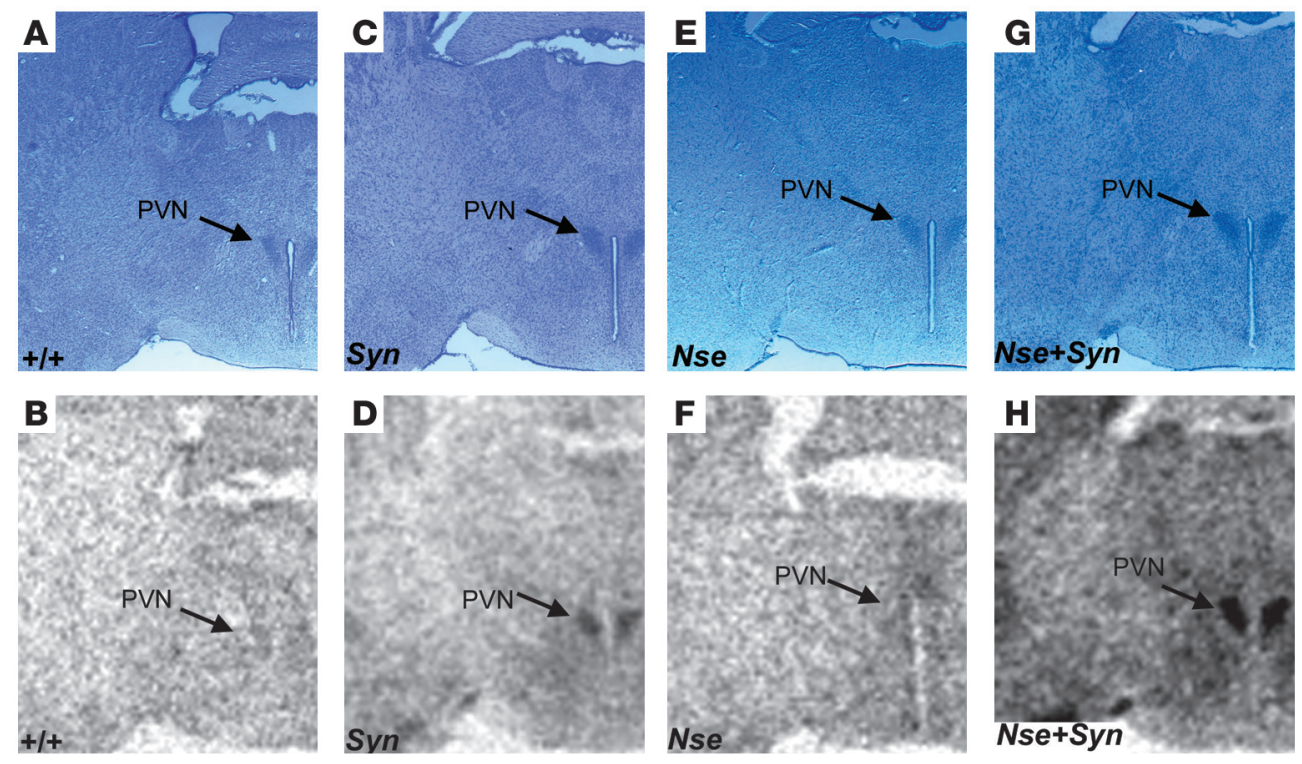

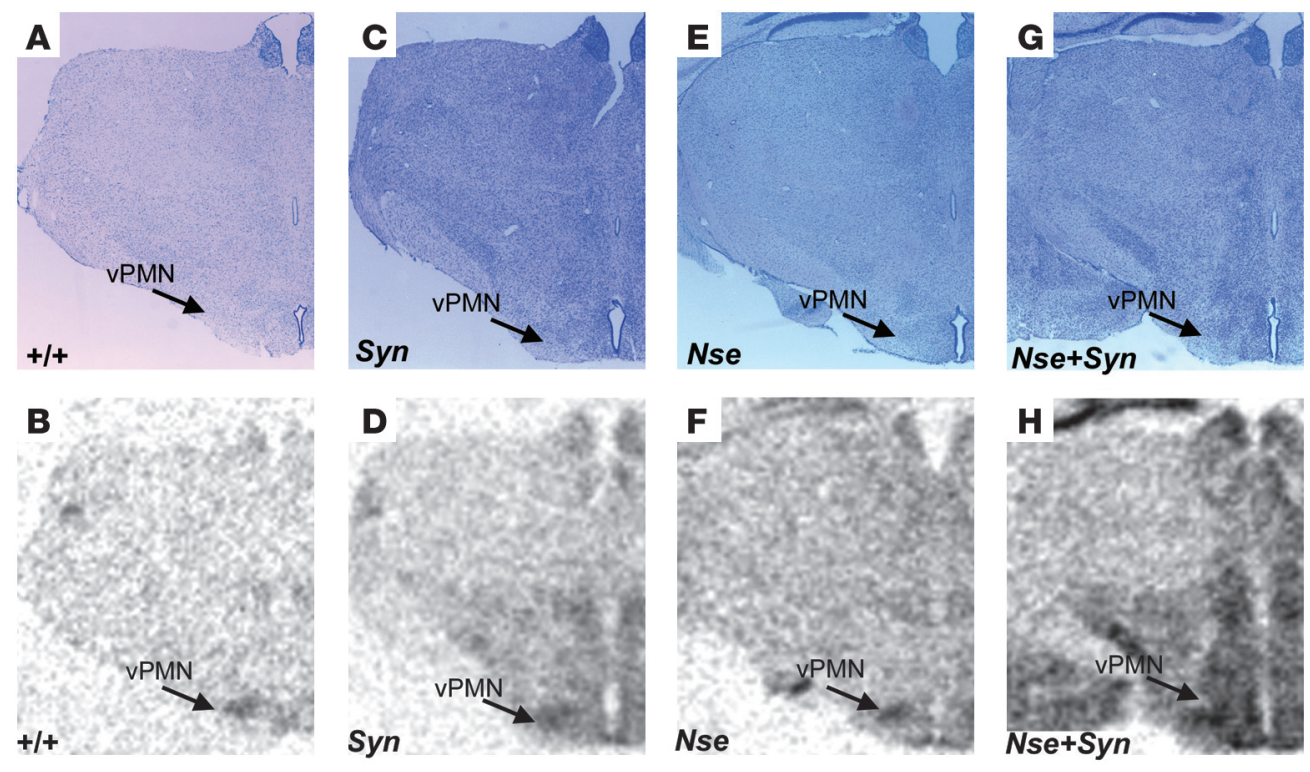

Figure 3

Transgene expression in ventral PMN (vPMN). In situ hybridization of LEPR-B mRNA in 25- $\mu$ M hypothalamic brain sections including vPMN. Two counterstained sections are represented in A, C, E, and G, and in situ hybridization autoradiographic images are represented in B, D, F, and $\mathbf{H}$. Genotypes are indicated. A and B represent $+/+$ mice, C and D represent Syn $d b / d b$ mice, E and $\mathbf{F}$ represent $N s e d b / d b$ mice, and $\mathbf{G}$ and $\mathbf{H}$ represent Nse+Syn $d b / d b$ mice. In the vPMN, there is weaker and more diffuse signal intensity from the SYN-LEPR-B transgene (D) in contrast to a more restricted and higher relative intensity signal from the NSE-LEPR-B transgene $(\mathbf{F})$. In $\mathbf{C}$, both transgenes combined increase signal intensity in the Nse+Syn $d b / d b$ mice. Magnification, $\times 20$.

$d b 3 \mathrm{~J} / \mathrm{db} 3 \mathrm{~J}$ mice (Figure 2, D, F, and $\mathrm{H}$ ). In addition to differences in relative levels of expression, we observed differences in spatial expression patterns. In the paraventricular nucleus (PVN), there was little detectable expression from the NSE-LEPR-B transgene while this region showed intense expression from the SYN-LEPR$\mathrm{B}$ transgene (Figure 2, D, F, and H). In the ventral premammilary nucleus (PMN), there was weak expression from the SYN-LEPR-B transgene but stronger expression from the NSE-LEPR-B transgene (Figure 3, D and $\mathrm{H}$ ). In addition, there was more expression from the SYN-LEPR-B transgene in the lateral hypothalamus (LH) than from the NSE-LEPR-B transgene (Figure 4, D and H). There was complementation of expression patterns in Nse+Syn $d b / d b$ hypothalami (Figure 2, D, F, and H; Figure 3, D, F, and H; and Figure 4, D, F, and H). We also examined expression of the transgene in the hindbrains of Nse+Syn $d b / d b$ and Syn $d b / d b$ mice. Syn $d b / d b$ mice showed mild expression in the nucleus of the tractus solitarius (NTS) and no expression in the area postrema whereas $N s e+S y n d b / d b$ mice showed strong expression in both of these regions (Supplemental Figure 2; supplemental material available online with this article; doi:10.1172/JCI24059DS1).

SYN-LEPR-B and NSE-LEPR-B transgenes separately attenuate body weight and adiposity of $d b / d b$ mice but completely normalize it when coexpressed. In males, the SYN-LEPR-B transgene appeared to have no effect on body weight when at least 1 wild-type allele of Lepr was present $(31.7 \pm 1.2 \mathrm{~g}$ versus $29.4 \pm 0.7 \mathrm{~g}$ for Syn $+/+$, Syn $\mathrm{db} /+$ versus lean controls, respectively; $P>0.05$ ) (Figure 5, Table 1, and Supplemental Figure 1A). We analyzed the impact of this transgene in mice with at least 1 wild-type Lepr allele and, at least under the described conditions, the transgene did not have an effect on body weight or body composition of either males or females
Nse+Syn $d b / d b$ male mice experienced a complete correction of their body weight $(26.5 \pm 0.9 \mathrm{~g} ; P>0.05)$ and adiposity $(20.3 \% \pm 0.8 \%$; $P>0.05$ ) when compared with lean controls (Table 1). A graphical representation of body composition shows that most of the correction in body weight conferred by the transgenes was due to a marked reduction in fat mass (Figure 5). However, there was a very small decrease in lean mass in $N s e+S y n d b / d b$ mice when compared with partially corrected Syn/Syn $d b / d b$, Syn $d b / d b$, and $d b / d b$ mice and lean controls.

A similar phenotype was observed in female SYN-LEPR-B transgenic mice when analyzed for body weight. In females, the SYNLEPR-B transgene appeared to have no effect on body weight when at least 1 wild-type allele of Lepr was present, Syn $+/+$ or Syn $d b /+$, when compared with lean controls $(23.4 \pm 0.8$ g vs. $23.0 \pm 0.8$ g respectively; $P>0.05)$ (Table 2 and Supplemental Figure 1B). Syn $d b / d b$ female mice experienced a large reduction in body weight $(30.5 \pm 1.5 \mathrm{~g})$ when compared with obese controls $(59.5 \pm 2.1 \mathrm{~g} ; P<0.001)$. However, they were still substantially heavier than lean controls $(P<0.05)$. We were unable to analyze female $S y n / S y n d b / d b$ mice because of difficulties in obtaining and propagating these mice. We did, however, examine $N s e+S y n d b / d b$ female mice and found that body weight $(20.5 \pm 0.5 \mathrm{~g})$ and adiposity $(20.2 \% \pm 1.3 \%)$ were completely normalized with no difference from lean controls (Table 2). We also found that the transgenes in female $d b / d b$ mice corrected adiposity by decreasing fat mass, similar to our observations in males (Figure 5).

Food intake is normalized in Nse+Syn $d b / d b$ mice. The lower body weight and reduced adiposity in Syn $d b / d b$, Syn/Syn- $d b / d b$, and $N s e+S y n d b / d b$ mice can be partially attributed to a significant decrease in caloric intake. The SYN-LEPR-B transgene caused a dose-dependent decrease in daily food intake as demonstrated in 

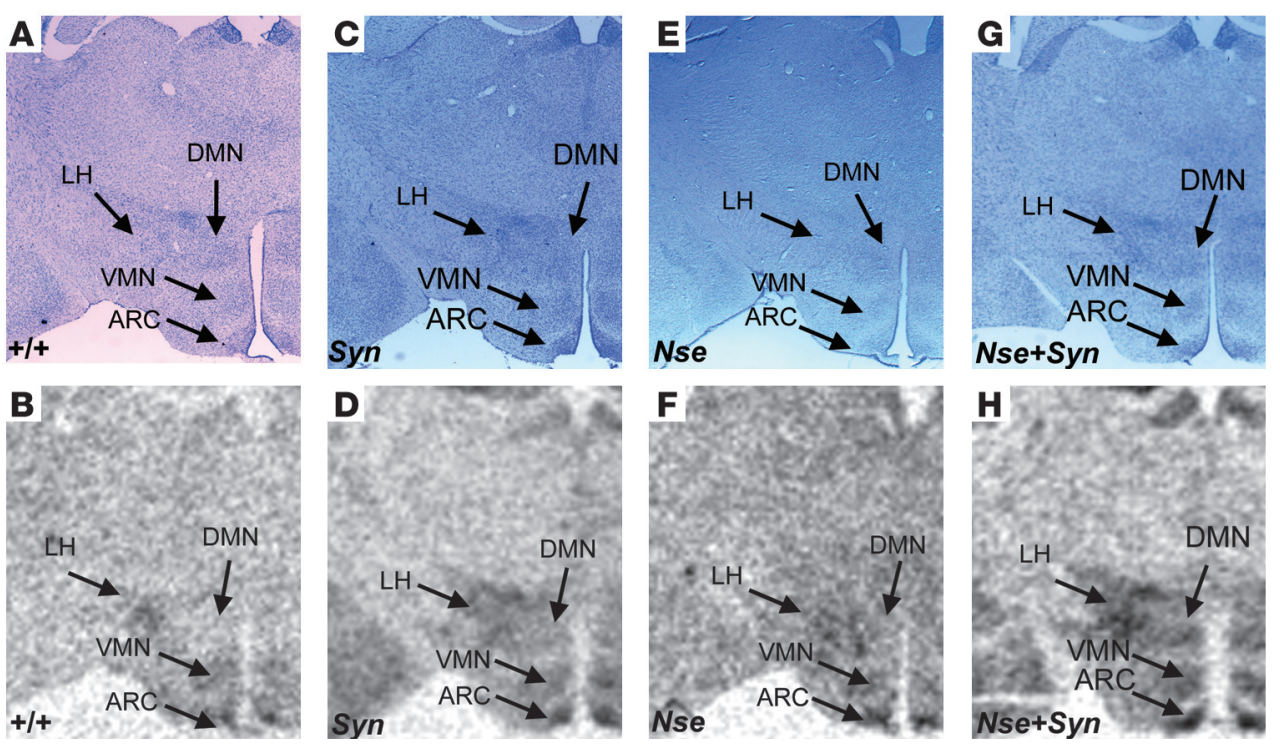

\section{Figure 4}

Transgene expression in the ARC, VMN, DMN, and LH. In situ hybridization of LEPR-B mRNA in hypothalamic brain sections, including $\mathrm{ARC}, \mathrm{VMH}, \mathrm{DMH}$, and $\mathrm{LH}$. Counterstained sections are represented in $\mathbf{A}$, $\mathbf{C}, \mathbf{E}$, and $\mathbf{G}$, and in situ hybridization autoradiographic images are represented in B, D, F, and $\mathbf{H}$. Genotypes are indicated. $\mathbf{A}$ and $\mathbf{B}$ represent $+/+$ mice, $\mathbf{C}$ and $\mathbf{D}$ represent Syn $d b / d b$ mice, $\mathbf{E}$ and $\mathbf{F}$ represent $N s e d b / d b$ mice, and $\mathbf{G}$ and $\mathbf{H}$ represent $N s e+S y n d b / d b$ mice. In the ARC, the SYN-LEPR-B and NSELEPR-B transgenes and wild-type LEPR-B are all expressed in the ARC. $\mathbf{H}$ shows a stronger signal, probably from the additive effect of the coexpression in both transgenes within the ARC. In the DMN, VMN, and $\mathrm{LH}$, there is a relatively stronger expression signal from the SYN-LEPR-B transgene (D) when compared with the NSE-LEPR-B transgene $(\mathbf{F})$. The additive and complementary effect of coexpression is observed in the VMN, DMN, and LH in this brain section from Nse+Syn $d b / d b$ mice $(\mathbf{H})$. Magnification, $\times 20$.
Syn $d b / d b$ mice $\left(-3.9 \pm 1.9^{\circ} \mathrm{C}\right.$, $n=8 ; P<0.001$ vs. $d b / d b)$, and when compared with $+/+$ mice $\left(-2.7 \pm 0.8^{\circ} \mathrm{C}, n=24\right)$, Nse + Syn $d b / d b$ and Syn $d b / d b$ mice were not statistically different in their ability to maintain core body temperature $(P>0.05$ for both), despite an apparent trend toward lower core temperatures in the transgenic mice.

Diabetic phenotype is reversed in $d b / d b$ mice with SYN-LEPR-B and NSE-LEPR-B transgenes. Insulin resistant diabetes is a major concomitant phenotype associated with obesity in $d b / d b$ mice. Male Syn $d b / d b$ mice showed an improvement in all measures of diabetes (Table 1 and Figure 6), including the homeostasis model assessment (HOMA) index. The SYN-LEPR-B transgene in males ameliorated insulin resistance in a dosage-dependent manner as seen with fasted and postprandial glucose and insulin levels in Syn/Syn $d b / d b$ compared with Syn $d b / d b$ mice. More striking was the impact of SYN-LEPR-B in combination with NSE-LEPR-B. Lean controls and $N s e+S y n d b / d b$ Syn $/$ Syn $d b / d b(3.8 \pm 0.3 \mathrm{~g} / \mathrm{d})$ and Syn $d b / d b$ male mice $(4.3 \pm 0.2 \mathrm{~g} / \mathrm{d}$; $P<0.001)$, and both were significantly different from obese controls $(7.8 \pm 0.1 \mathrm{~g} / \mathrm{d} ; P<0.001)$ (Table 1$)$. In male Nse+Syn $d b / d b$ mice, the transgenes completely normalized food intake $(3.1 \pm 0.1 \mathrm{~g} / \mathrm{d})$ when compared with lean controls $(3.3 \pm 0.2 \mathrm{~g} / \mathrm{d}$; $P>0.05)$. A similar pattern of correction was observed in female mice. Female Syn $d b / d b$ mice ate significantly less $(3.4 \pm 0.1 \mathrm{~g} / \mathrm{d})$ than obese controls $(6.4 \pm 0.1 \mathrm{~g} / \mathrm{d} ; P<0.001)$ but more than lean controls $(2.6 \pm 0.2 \mathrm{~g} / \mathrm{d} ; P<0.001)$. Female Nse $+S y n d b / d b$ mice had daily food intake $(2.4 \pm 0.2 \mathrm{~g} / \mathrm{d})$ similar to that of lean controls $(2.6 \pm 0.2 \mathrm{~g} / \mathrm{d} ; P>0.05)$ (Table 2$)$.

Cold intolerance is improved in Syn $\mathrm{db} / \mathrm{db}$ and Nse+Syn $\mathrm{db} / \mathrm{db}$ mice. Restoration of leptin signaling in the brain reversed the cold intolerance of $d b / d b$ mice. Exposure to an ambient temperature of $0-2^{\circ} \mathrm{C}$ for 1 hour resulted in a core body temperature loss of $8.0 \pm 3.1^{\circ} \mathrm{C}$ in $d b / d b$ mice due to impaired thermogenic capacity. This drop in core body temperature was prevented in Nse+Syn $d b / d b$ mice $\left(-4.3 \pm 0.7^{\circ} \mathrm{C}, n=8 ; P<0.001\right.$ vs. $\left.d b / d b\right)$ and

\section{Figure 5}

Body composition analysis. (A) Fat mass and lean mass are normalized in male Nse+Syn $d b / d b$ mice, but also note the partial decrease in fat mass in both Nse $d b / d b$ and Syn/Syn $d b / d b$ males. (B) Fat mass and lean mass are normalized in female Nse+Syn $d b / d b$ mice. There is a partial correction of both lean and fat mass in Nse $d b / d b$ female mice. ${ }^{\star} P<0.05$ vs. $+/+, d b /+;{ }^{*} P<0.05$ vs. Nse+Syn $d b / d b ;{ }^{\dagger} P<0.05$ vs. $d b / d b$. Fat mass is indicated by white component of column. Lean mass is indicated by black component of column. Values are mean \pm SEM. mice had HOMA index values of $25.7 \pm 1.4$ and $29.0 \pm 5$.6, indicating normal insulin sensitivity conferred by the 2 transgenes in combination. A significant correction of glucose metabolism was also observed in female transgenic mice. Syn $d b / d b$ mice had vastly improved glucose control as measured by both HOMA $(22.1 \pm 8.2)$ and the quantitative insulin sensitivity check index (QUICKI) $(0.424 \pm 0.05)$ (data not shown), both of which showed significant differences from results in obese controls. Compared with the HOMA index for lean controls $(7.6 \pm 1.7 ; P=0.006)$, that for Syn $d b / d b$ mice appeared to show slightly more insulin resistance

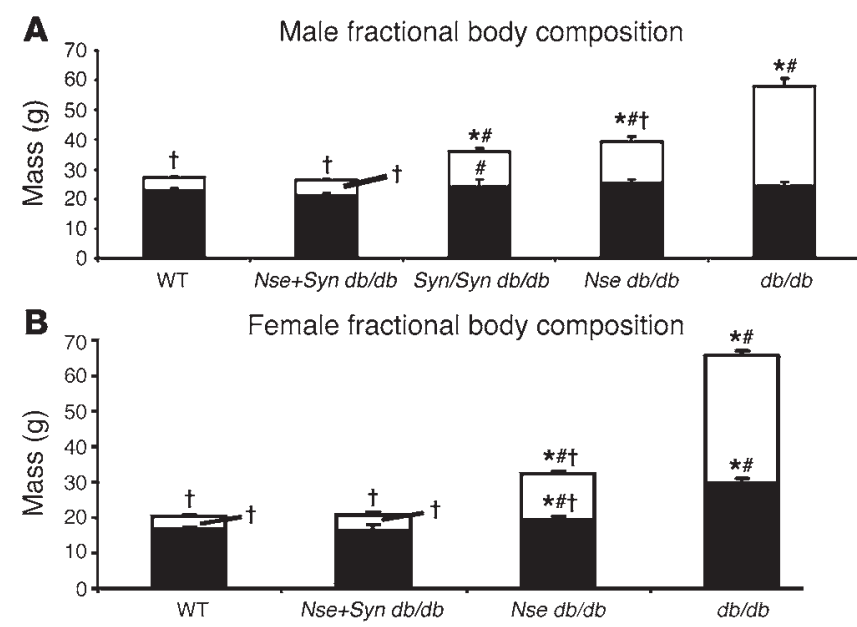




\section{Table 1}

Impact of LEPR-B transgenes on body composition, feeding, and glucose handling of male mice

\begin{tabular}{|c|c|c|c|c|c|c|c|}
\hline & \multicolumn{7}{|c|}{ Genotypes } \\
\hline & $\begin{array}{c}+/+, d b /+ \\
\text { Nse } d b /+\end{array}$ & $\begin{array}{l}\text { Syn +/+, } \\
\text { Syn } d b /+\end{array}$ & $N s e+S y n d b / d b$ & Syn/Syn $d b / d b$ & Syn $d b / d b$ & Nse $d b / d b$ & $d b / d b$ \\
\hline Weight (g) & $29.4 \pm 0.7(22)^{A}$ & $31.7 \pm 1.2(13)^{A, B}$ & $26.5 \pm 0.9(16)^{A}$ & $32.8 \pm 1.9(4)^{\mathrm{A}}$ & $38.8 \pm 4.4(4)^{A, B, C}$ & $38.9 \pm 1.0(6)^{A, B, C}$ & $54.5 \pm 2.5(12)^{\mathrm{B}, \mathrm{C}}$ \\
\hline Body fat (\%) & $16.0 \pm 0.7(13)^{A}$ & ND & $20.3 \pm 0.8(13)^{A}$ & $31.3 \pm 2.1(4)^{A, B, C}$ & ND & $35.0 \pm 3.8(5)^{A, B, C}$ & $54.5 \pm 1.7(10)^{\mathrm{B}, \mathrm{C}}$ \\
\hline $\begin{array}{l}\text { Fat-free } \\
\text { mass }(g)\end{array}$ & $23.0 \pm 0.4(14)$ & ND & $21.0 \pm 0.9(13)^{\mathrm{A}}$ & $24.0 \pm 2.6(4)^{\mathrm{B}}$ & ND & $25.4 \pm 1.3(5)$ & $24.3 \pm 1.2(10)$ \\
\hline Fat mass $(\mathrm{g})$ & $4.214 \pm 0.2(14)^{A}$ & ND & $5.354 \pm 0.2(13)^{A}$ & $11.81 \pm 1.3(4)^{\mathrm{A}, \mathrm{B}, \mathrm{C}}$ & ND & $13.8 \pm 1.9(5)^{A, B, C}$ & $33.63 \pm 2.8(10)^{B, C}$ \\
\hline $\begin{array}{l}\text { Naso-anal } \\
\text { length (cm) }\end{array}$ & $10.1 \pm 0.04(9)^{A}$ & ND & $10.2 \pm 0.04(9)^{\mathrm{A}}$ & $10.4 \pm 0.03(4)^{A, B, C}$ & ND & $10.5 \pm 0.05(5)^{A, C}$ & $11.1 \pm 0.05(10)^{B, C}$ \\
\hline $\begin{array}{l}\text { Food } \\
\text { intake }(\mathrm{g} / \mathrm{d})\end{array}$ & $3.1 \pm 0.1(19)^{A}$ & $2.8 \pm 0.2(8)^{A}$ & $3.3 \pm 0.2(4)^{A}$ & $3.8 \pm 0.3(4)^{A, B, C}$ & $4.3 \pm 0.2(8)^{A, B, C}$ & $4.8 \pm 0.1(8)^{A, B, C}$ & $7.8 \pm 0.1(16)^{B, C}$ \\
\hline $\begin{array}{l}\text { Fasted } \\
\text { glucose } \\
(\mathrm{mg} / \mathrm{dl})\end{array}$ & $97.8 \pm 4.0(32)^{\mathrm{A}}$ & $100.2 \pm 5.8(13)^{A}$ & $114.2 \pm 10.5(5)^{A}$ & $131.4 \pm 8.0(4)^{A}$ & $101.2 \pm 12.7(8)^{A}$ & $132.2 \pm 8.9(5)^{A}$ & $244.2 \pm 38.7(13)^{\mathrm{B}, \mathrm{C}}$ \\
\hline $\begin{array}{l}\text { Nonfasted } \\
\text { glucose } \\
(\mathrm{mg} / \mathrm{dl})\end{array}$ & $149.6 \pm 4.1(32)^{\mathrm{A}}$ & $153.7 \pm 7.4(13)^{\mathrm{A}}$ & $156.6 \pm 4.1(5)^{\mathrm{A}}$ & $144 \pm 12.2(4)^{A}$ & $272.3 \pm 43.8(8)^{\mathrm{A}, \mathrm{C}}$ & $159.2 \pm 6.1(5)^{A}$ & $445.7 \pm 45.6(13)^{B, C}$ \\
\hline $\begin{array}{l}\text { Fasted } \\
\text { insulin } \\
(\mathrm{ng} / \mathrm{ml})\end{array}$ & $0.46 \pm 0.07(36)^{A}$ & $0.38 \pm 0.14(13)^{A}$ & $0.50 \pm 0.08(5)^{A}$ & $0.8 \pm 0.15(4)$ & $2.67 \pm 1.18(8)$ & $1.6 \pm 0.19(4)^{A}$ & $10.44 \pm 3.67(10)^{B, C}$ \\
\hline $\begin{array}{l}\text { Nonfasted } \\
\text { insulin } \\
\text { (ng/ml) }\end{array}$ & $0.99 \pm 0.15(51)^{A}$ & $1.46 \pm 0.2(13)^{A}$ & $0.96 \pm 0.11(5)^{A}$ & $1.25 \pm 0.39(4)^{A}$ & $16.57 \pm 5.23(8)$ & $5.0 \pm 1.69(5)^{A, C}$ & $25.78 \pm 10.20(11)^{B, C}$ \\
\hline HOMA index & $25.7 \pm 1.4(9)^{A}$ & $20.1 \pm 6.0(8)^{A}$ & $29.0 \pm 5.6(5)^{A}$ & $52.7 \pm 10.1(4)^{A}$ & $268.3 \pm 147(5)^{A, C}$ & $95.6 \pm 18.3(5)^{\mathrm{A}}$ & $369 \pm 112(5)^{c}$ \\
\hline
\end{tabular}

Analysis of effects of the NSE-LEPR-B and SYN-LEPR-B transgenes on obesity and diabetes in male $d b / d b$ mice. ${ }^{A} P<0.05$ vs. $d b / d b$; ${ }^{B} P<0.05$ vs.

$N$ se + Syn $d b / d b ; C P<0.05$ vs. $+/+, d b /+$. Values are mean \pm SEM. ND, not determined. Numbers in parentheses indicate number of animals in each group.

(Table 2). Immunohistochemical analyses of pancreatic sections revealed normal islet morphology in male $N s e+S y n d b / d b$ mice and a dose-dependent correction of enlarged pancreatic islets in Syn $d b / d b$ and Syn/Syn $d b / d b$ mice (Figure 7).

Coexpression of SYN-LEPR-B and NSE-LEPR-B transgenes corrects bypothalamic Npy, Agrp, and Pomc expression in $d b / d b$ mice. There were significant decreases in levels of expression, as detected by real-time quantitative PCR, of Npy in Nse+Syn $d b / d b$ mice when compared with $d b / d b$ mice and no differences in Npy expression between lean control mice and $N s e+S y n d b / d b$ mice (Figure 8A). Agrp expression was also significantly decreased in $N s e+S y n d b / d b$ mice when compared with $d b / d b$ mice (Figure $8 \mathrm{~B}$ ). Pomc expression levels in lean mice were similar to those of Nse+Syn $d b / d b$ mice (Figure 8C). While there was a trend for lower POMC mRNA in $N s e+S y n d b / d b$ mice relative to lean mice, the difference did not reach statistical significance $(P=0.07)$

SYN-LEPR-B and NSE-LEPR-B transgenes in combination completely restore fertility in male and female $d b / d b$ mice. Leptin signaling is required for normal fertility as demonstrated by the infertility of $o b / o b$ and $d b / d b$ mice. The SYN-LEPR-B transgene showed a dose-dependent amelioration of the infertility of $d b / d b$ male and

\section{Figure 6}

Glucose-insulin plots in fasting male mice. See plot for genotype and plot point assignment. This graphical representation of glucose metabolism in fasted male mice shows the ability of the SYN-LEPR-B and NSE-LEPR-B transgenes to ameliorate the diabetes phenotype in Nse $d b / d b$, Syn $d b / d b$, and Syn/Syn $d b / d b$ mice and to completely correct it in Nse+Syn $d b / d b$ mice. Values are mean \pm SEM. female mice. All female Syn $d b / d b$ females were able to become pregnant and deliver normal-sized litters. However, the duration of time between mating pair setup and the birth of the first litter in Syn $d b / d b$ females was 65.7 days, 52 days in Syn/Syn $d b / d b$ mice, whereas in wild-type mice this period is typically $21-26$ days (C. de Luca, unpublished observations). Nse+Syn $d b / d b$ females' duration of time between mating pair setup and the birth of the first litter was 24.4 days. In addition, all 5 females tested produced litters of 8 or more pups (Table 3). Male Syn $d b / d b$ and Syn/Syn $d b / d b$ mice showed a fertility phenotype similar to that of their female counterparts. Male Syn $d b / d b$ mice only produced offspring in 3 of 7 matings and experienced a delay similar to that seen in the females of 60.3 days. The 2 Syn/Syn $d b / d b$ male mice tested were able to sire litters with less delay (36 days) than Syn $d b / d b$ males (60.3 days).

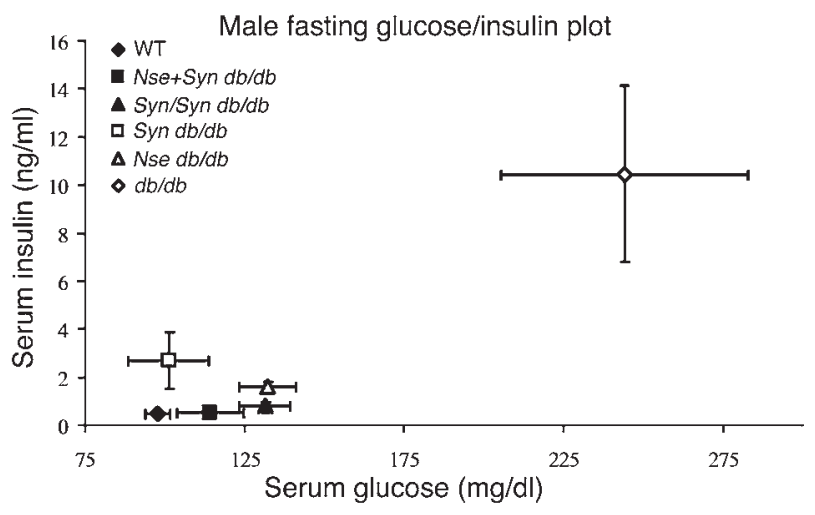




\section{Table 2}

Impact of LEPR-B transgenes on body composition, feeding, and glucose handling of female mice

\begin{tabular}{|c|c|c|c|c|c|c|c|}
\hline & \multicolumn{7}{|c|}{ Genotypes } \\
\hline & $\begin{array}{c}+/+, d b /+ \\
\text { Nse } d b /+\end{array}$ & $\begin{array}{l}\text { Syn }+/+ \\
\text { Syn } d b /+\end{array}$ & $\begin{array}{c}\text { Nse+Syn } \\
d b / d b\end{array}$ & $\begin{array}{c}\text { Syn/Syn } \\
d b / d b\end{array}$ & $\begin{array}{c}\text { Syn } \\
d b / d b\end{array}$ & $\begin{array}{c}N s e \\
d b / d b\end{array}$ & $d b / d b$ \\
\hline Weight (g) & $23.0 \pm 0.8(33)^{A}$ & $23.4 \pm 0.6(17)^{\mathrm{A}}$ & $20.5 \pm 0.5(11)^{A}$ & ND & $32.6 \pm 2.1(5)^{A, B, C}$ & $32.4 \pm 1.1(10)^{A, B, C}$ & $59.5 \pm 2.1(10)^{\mathrm{B}, \mathrm{C}}$ \\
\hline Body fat $(\%)$ & $17.5 \pm 0.7(13)^{\mathrm{A}}$ & ND & $20.2 \pm 1.3(10)^{A}$ & ND & ND & $39.6 \pm 1.3(7)^{A, B, C}$ & $54.2 \pm 3.7(5)^{\mathrm{B}, \mathrm{C}}$ \\
\hline Fat free mass $(\mathrm{g})$ & $16.8 \pm 0.7(13)^{A}$ & ND & $16.5 \pm 0.4(10)^{A}$ & ND & ND & $19.5 \pm 0.6(7)^{A, B, C}$ & $29.7 \pm 1.4(5)^{\mathrm{B}, \mathrm{C}}$ \\
\hline Fat mass $(\mathrm{g})$ & $3.6 \pm 0.3(13)^{A}$ & ND & $4.2 \pm 0.3(10)^{A}$ & ND & ND & $12.9 \pm 1.0(7)^{A, B, C}$ & $36.1 \pm 5.1(5)^{B, C}$ \\
\hline Naso-anal length (cm) & $9.6 \pm 0.06(10)^{A}$ & ND & $9.6 \pm 0.07(10)^{A}$ & A ND & ND & $10.0 \pm 0.06(7)^{A, B, C}$ & $11.0 \pm 0.2(4)^{A, B, C}$ \\
\hline Food intake $(g / d)$ & $2.6 \pm 0.2(16)^{A}$ & ND & $2.4 \pm 0.2(8)^{A}$ & ND & $3.4 \pm 0.1(8)^{A, B}$ & $3.6 \pm 0.3(12)^{A, B, C}$ & $6.4 \pm 0.1(13)^{\mathrm{B}, \mathrm{C}}$ \\
\hline Fasted glucose (mg/dl) & $85.6 \pm 3.2(36)^{A}$ & $86.1 \pm 5.3(17)^{\mathrm{A}}$ & $93.1 \pm 5.9(7)^{A}$ & ND & $88.1 \pm 5.7(10)^{\mathrm{A}}$ & $146 \pm 19(3)^{A}$ & $222 \pm 38(14)^{B, C}$ \\
\hline Non-fasted glucose (mg/dl) & $126 \pm 4.6(36)^{\mathrm{A}}$ & $118 \pm 9.0(17)^{\mathrm{A}}$ & $122 \pm 7.0(7)^{\mathrm{A}}$ & ND & $137 \pm 6.2(10)^{A}$ & $139 \pm 5(3)^{A}$ & $399 \pm 36(14) B, C$ \\
\hline Fasted insulin (ng/ml) & $0.17 \pm 0.04(28)^{A}$ & $0.16 \pm 0.05(17)^{\mathrm{A}}$ & ND & ND & $0.43 \pm 0.16(10)^{\mathrm{A}}$ & ND & $3.4 \pm 0.5(9)^{\mathrm{B}, \mathrm{C}}$ \\
\hline Nonfasted insulin (ng/ml) & $0.68 \pm 0.1(26)^{A}$ & $0.81 \pm 0.1(17)^{\mathrm{A}}$ & ND & ND & $1.34 \pm 0.4(9)^{\mathrm{A}}$ & ND & $19.2 \pm 8.5(8)^{\mathrm{B}, \mathrm{C}}$ \\
\hline HOMA index & $7.6 \pm 1.7(26)^{A}$ & $6.7 \pm 2.0(17)^{\mathrm{A}}$ & ND & ND & $22.1 \pm 8.2(9)^{B, A}$ & ND & $536 \pm 172(8)^{\mathrm{B}, \mathrm{D}}$ \\
\hline
\end{tabular}

Analysis of effects of the NSE-LEPR-B and SYN-LEPR-B transgenes on obesity and diabetes in female $d b / d b$ mice. ${ }^{A} P<0.05$ vs. $d b / d b$; ${ }^{B} P<0.05$ vs. Nse+Syn $d b / d b ; C P<0.05$ vs. $+/+, d b /+$; and ${ }^{D} P<0.05$ vs. Syn $d b / d b$ for female fasting and nonfasting insulin and HOMA only. Values are mean \pm SEM. Numbers in parentheses indicate number of animals in each group.

Male Nse+Syn $d b / d b$ mice were completely normal, with 21.2 days from the mating setup date to the birth of the first litter; all 5 males tested sired litters of 8 pups or more (Table 3 ).

Deletion of peripheral signaling LEPR has no effect on adiposity. To directly assess the role of peripheral LEPR in the regulation of adiposity, we generated a mouse model of somatic chimerism with deletion of the signaling motifs of LEPR restricted to peripheral tissues by conditional gene inactivation using a tamoxifen-inducible (Tam-inducible) CRE-ER ${ }^{\mathrm{T} 2}$ transgene (16-19). Deletion of exon 17 was induced with Tam i.p. at $1 \mathrm{mg} /$ day for 5 days. This regimen produced no deletion of exon 17 of Lepr in the brain and hypothalamus but substantial deletion of exon 17 in the liver, pancreas, small intestine, and white adipose tissues of Leprflox/flox; ROSA26CRE-ERT2/+ mice (Figure 9A). Body composition determinations by dual energy X-ray absorptiometry (DEXA) analysis 3 months after Tam treatment revealed no differences in either body weight or fat mass between Cre+Tam and nonCre+Tam mice (Figure 9B).

\section{Discussion}

We have previously shown that the NSE-LEPR-B transgene has effects on all aspects of obesity caused by disruptions of leptin signaling in $d b / d b$ mice $(10,20)$. Mice that are hemizygous for the transgene and LEPR deficient ( $d b$ and $\left.d b^{3}\right)$ ) were leaner and less insulin resistant and had normal cold tolerance. Males regained fertility while females remained infertile. Pomc expression was normalized although Agrp and Npy were only partially normalized. We then showed the effect of the transgene in the homozygous state in $d b / d b$ mice. We reasoned that increasing the dosage of the transgene would increase the expression of LEPR-B and allow for greater correction of the obese phenotype in $d b / d b$ mice. The increased transgene dosage further reduced the adiposity in male $d b / d b$ mice and that in female $d b / d b$ mice to a lesser degree. Glucose metabolism was partially corrected in the transgenic mice, but they still retained mild insulin resistance. The fertility and ability to lactate was completely restored in female transgenic mice. NSE-LEPR-B was effective in a dose-dependent manner in ameliorating nearly all major phenotypes associated with LEPR deficiency. However, 2 questions remain in regard to the ability of the NSE-LEPR-B transgene to rescue all aspects of the LEPR deficiency phenotype: (a) Is leptin signaling in peripheral organs the reason that neuronspecific LEPR-B expression fails to completely correct the obese phenotype of $d b / d b$ mice? (b) Are all the relevant neurons in the hypothalamus and other regions of the brain responsible for mediating LEPR-B signaling sufficiently expressing the transgene?

In this study, we use the SYN I promoter to confer neuron-specific expression of LEPR-B. Expression analysis of the transgene confirmed neuron-specific expression in the tissues examined although we did not examine expression in peripheral nerves, such as the vagus nerve, which has been shown to be leptin sensitive and to affect feeding behavior $(21,22)$. We observed a similar amelioration of the obesity and diabetic phenotypes as we did with the NSE-promoter driven transgene. The transgene had no apparent effect on the phenotype of $d b /+$ or $+/+$ mice, indicating

Table 3

Restoration of fertility in male and female $d b / d b$ mice by LEPR-B transgenes

\begin{tabular}{|c|c|c|c|}
\hline Female fertility & Nse+Syn $d b / d b$ & Syn/Syn $d b / d b$ & Syn $d b / d b$ \\
\hline Females mated $(n)$ & 5 & 3 & 3 \\
\hline No. pregnancies & 5 & 3 & 3 \\
\hline $\begin{array}{l}\text { Days from mating to } \\
\text { delivery of first litter }\end{array}$ & $24.4(22-27)$ & 52 & $65.7(52-93)$ \\
\hline Pups/litter ( $n)$ & $>8$ & $>8$ & $>8$ \\
\hline Pups weaned $(n)$ & $>8$ & $>8$ & ND \\
\hline Male fertility & $N s e+S y n d b / d b$ & Syn/Syn $d b / d b$ & Syn $d b / d b$ \\
\hline Males mated $(n)$ & 5 & 2 & 7 \\
\hline No. pregnancies & 5 & 2 & 3 \\
\hline $\begin{array}{l}\text { Days from mating to } \\
\text { delivery of first litter }\end{array}$ & $21.2(21-22)$ & 36 & $60.3(36-93)$ \\
\hline Pups/litter ( $n)$ & $>8$ & $>8$ & $>8$ \\
\hline Pups weaned $(n)$ & $>8$ & ND & ND \\
\hline
\end{tabular}

Assessment of effects of the NSE-LEPR-B and SYN-LEPR-B transgenes on fertility. Values are reported as means with ranges in parentheses. All mice were mated at 6 weeks of age. Data provided are for the first litters produced. 


\section{Table 4}

Summary of LEPR-B transgene expression by in situ hybridization

\begin{tabular}{lcccc} 
& \multicolumn{4}{c}{ Genotypes } \\
& WT & $\begin{array}{c}\text { Syn } \\
d b / d b\end{array}$ & $\begin{array}{c}\text { Nse+Syn } \\
d b / d b\end{array}$ & $\begin{array}{c}\text { Nse } \\
\text { db/db }\end{array}$ \\
Hypothalamic nuclei & & & & \\
PVN & & & & \\
ARC & + & ++ & +++ & - \\
DMN & + & ++ & +++ & + \\
VMN & - & ++ & +++ & + \\
PMN, ventral & + & + & ++ & - \\
LH & + & ++ & +++ & + \\
Hindbrain & & & & \\
Area postrema & ND & + & ++ & ND \\
NTS & ND & + & ++ & ND \\
\hline
\end{tabular}

Relative expression of the SYN-LEPR-B and NSE-LEPR-B transgenes within relevant brain regions and the effect of coexpression.

that increasing LEPR number by transgenic overexpression did not alter body weight under the conditions described (Supplemental Figure 1, A and B). The body weight of the Syn $d b / d b$ mice was decreased in both males and females when compared with $d b / d b$ controls but remained significantly heavier than in lean controls. The data indicated a partial correction of food intake due to expression of the transgene.

We examined insulin sensitivity by calculating HOMA index values. Male Syn $d b / d b$ mice were insulin resistant while females exhibited a milder insulin resistance. However, Nse $d b / d b$ mice did not exhibit such a level of insulin resistance despite a similar degree of adiposity. This may be explained in part by the normalization of POMC expression in Nse $d b / d b$, mice as the central melanocortin system modulates insulin release and peripheral insulin sensitivity before the onset of obesity in melanocortin 4 receptor knockout mice $\left(\mathrm{Mc}_{4 r^{-1}}\right)$ (23).

We carried out fertility studies to assess the ability of the SYN-LEPR-B transgene to correct the infertility of $d b / d b$ mice and found that, although fertility was restored in females, the length until the birth of their first litter was 40 days later than in lean controls. Fewer than half of the males tested were able to sire litters, and they did so with a similar delay in gestation as in transgenic $d b / d b$ females. It is possible that the SYN-LEPR-B transgene did not correct behavioral abnormalities in $d b / d b$ males although we did not measure androgens, which may have remained abnormally low. It is also possible that alterations in estrus cycling and aborted pregnancies may have played a role in the female's subfertility. These parameters were not measured in this study and warrant further investigation.

Syn $d b / d b$ mice showed a partial correction of the obesity and related phenotypes similar to the correction in $N s e d b / d b$ mice despite the relatively higher level of expression from the SYN-LEPR-B transgene. We carried out an examination of the effect of the SYN-LEPR-B transgene in the homozygous state to determine the effect of increasing dosage of the transgene on the degree of correction. Syn/Syn $d b / d b$ males had body weights similar to those of lean controls but differed in body composition, showing an increase in fat mass. These mice also exhibited a greater degree of insulin sensitivity than the Syn $d b / d b$ mice. Daily food intake in these mice was decreased as well. Fertility was also improved, and the delay in pregnancy and delivery we observed in $S y n d b / d b$ mice was shortened significantly in both males and females. In summary, the SYN-LEPR-B transgene was able to confer a dosedependent rescue of the obese phenotype in $d b / d b$ mice though a full correction was not obtained.

We believe that while leptin signaling in the brain is required to normalize energy balance of $d b / d b$ mice, we have shown that it cannot be fully achieved with the expression of either the NSE-LEPRB or SYN-LEPR-B transgenes in the hemizygous or homozygous state. The reason for this inability to completely correct the obesity/diabetes phenotype is made evident by examining the strength and pattern of transgene expression conferred by each transgene from the in situ hybridization data (summarized in Table 4). We examined the relative strengths of expression of the transgenes and found that the SYN-LEPR-B transgene was more highly expressed in the brain in general and particularly in the hypothalamus compared with both the NSE-LEPR-B transgene and endogenous Lepr. This is of interest because we initially reported a gene dosage effect in the NSE-LEPR-B transgenic animals, but these data suggest that even at very high levels of expression of LEPR-B, as in the SYNLEPR-B transgenic mice, gene dosage is not likely the only factor involved in faithfully restoring leptin signaling to correct the obese phenotype of $d b / d b$ mice. Examining the pattern of expression, we found that the NSE-LEPR-B transgene was not expressed in the PVN and was weakly expressed in the ventromedial nucleus (VMN), both of which contain neurons that are sensitive to leptin, as shown by immunohistological analysis of STAT3 phosphorylation upon leptin stimulation $(24,25)$. We also found that the SYN-LEPR-B transgene, while providing a more intense expression signal overall, showed a weaker signal in the PMN compared
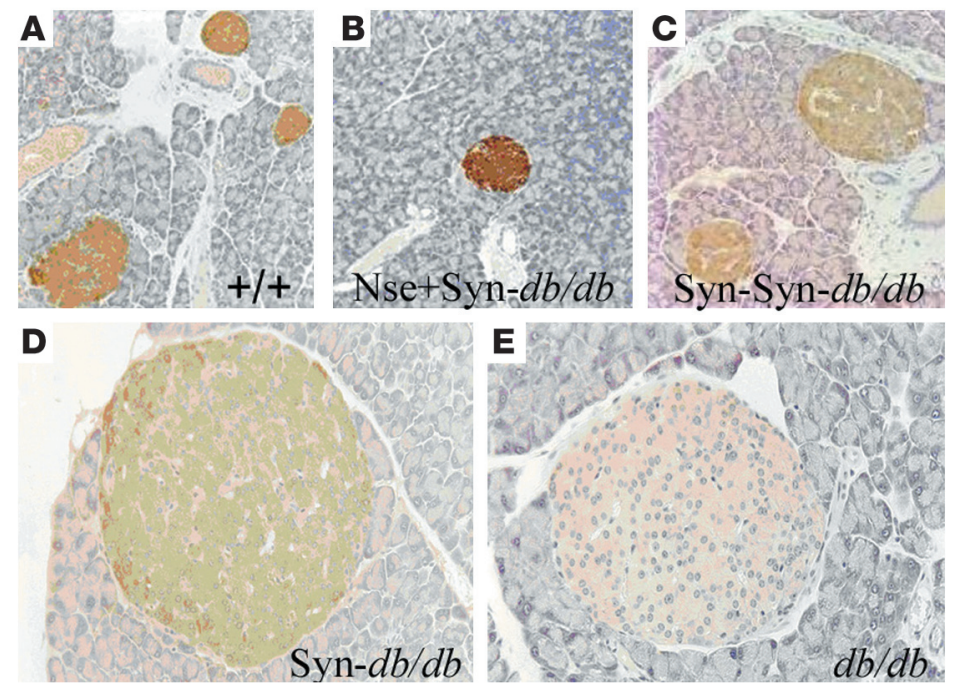

\section{Figure 7}

Normalization of pancreatic islet morphology in males. (A and B) Nse+Syn $d b / d b$ and $+/+$ mice have comparable islet morphology. (C and D) The SYNLEPR-B transgene shows a dosage-dependent rescue of islet morphology. (E) Obese control demonstrating enlarged pancreatic islet. Genotypes are indicated. Magnification, $\times 20$. 

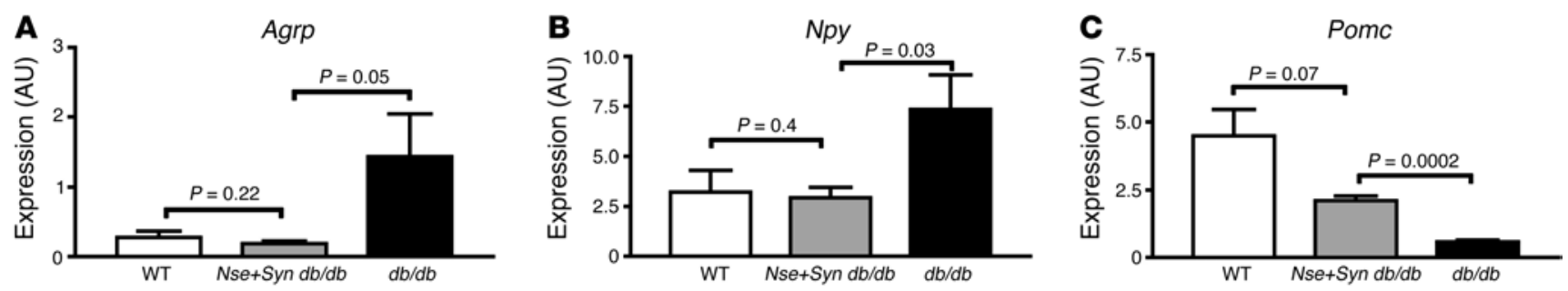

Figure 8

Trangene effect on hypothalamic neuropeptide gene expression. (A) Agrp expression is normalized in Nse+Syn $d b / d b$ mice compared with $+/+$. (B) Npy expression is normalized in Nse+Syn $d b / d b$ mice compared with $+/+$. (C) Pomc expression is normalized in Nse+Syn $d b / d b$ mice compared with $+/+$. $P$ values are indicated. Values are mean \pm SEM.

with the NSE-LEPR-B transgene. We wish to note that this hypothalamic area is related to pheromonal stimulation in males and females with projections, some of which express CART, to gonadotropin-releasing hormone ( $\mathrm{GnRH}$ ) neurons in the medial preoptic area (26-29), pointing to a potential role of these areas for leptin regulation of sexual development and/or reproduction. We do not know which cells within these hypothalamic nuclei are expressing the transgene. However, our data suggest that expression patterns of the individual transgenes alone cannot fully reproduce native leptin signaling in the brain and that increasing expression only supplements the established pattern. This observation led us to ask the question: Can both transgenes together effectively restore brain-specific leptin signaling by complementation that would more effectively rescue the obese phenotype of $d b / d b$ mice?

The data presented show that the compound transgenic mice are indistinguishable from lean controls. Specifically, body weight and body composition, ad libitum food intake, insulin sensitivity, cold tolerance, and fertility of the compound transgenic mice were fully normalized to the levels of lean controls. Furthermore, we found normalization of Npy, Agrp, and Pomc mRNA levels in $d b / d b$ mice by the 2 transgenes. This finding is consistent with the absence of hyperphagia and normalized body composition in these animals.

Male and female Nse+Syn $d b / d b$ mice were both fertile. Nse+Syn $d b / d b$ mice produced normal-sized litters without the delay we observed in SYN-LEPR-B transgenic mice. Recent work suggests the mechanism of fertility restoration is independent of STAT3 signaling by showing a partial restoration of fertility in mice with LEPRs deficient in their ability to phosphorylate STAT3, demonstrating that LEPR probably mediates its effects on NPY via other signal transduction pathways such as PI3K or extracellular signal-regulated kinase ERK (30). Sainsbury et al., also showed that a deletion of NPY receptor $Y 4$, a G-protein coupled receptor that does not couple to the JAK-STAT pathway directly, rescues the fertility of $o b / o b$ mice, implicating elevated NPY levels as a major cause of infertility in $o b / o b$ and $d b / d b$ mice (31). We propose that the transgene's effect on normalizing NPY levels contributes to the restoration of fertility in Nse+Syn $d b / d b$ mice.

$N s e+S y n d b / d b$ female mice, in addition to being fertile, were able to nurture their pups. It has been demonstrated that leptin is required for the normal development of the mammary gland (32). Treatment of $o b / o b$ female mice with leptin until $6.5 \mathrm{dpc}$ (days post coitum)

A permitted conception, implantation, and gestation but resulted in failure of the pups to thrive due to the mother's inability to lactate. However, continuous leptin treatment of $o b / o b$ females prior to pregnancy and beyond parturition allows for normal mammary gland development and pup survival (32). Further evidence for leptin's role in lactation can be seen in female $Y_{4 R^{-/-}}$ob/ob double knockout mice that are fertile but have poorly developed mammary glands that are unable to lactate sufficiently (31). Mice with defective LEPR-B STAT3 signaling are also fertile but unable to lactate, suggesting that leptin mediates its role in the control of lactation via the LEPR-B STAT3-signaling pathway (30). It is not known if the inability to lactate in these mice is due to improper mammary gland development or insufficient lactogenesis. Our data suggest that neuron-specific LEPR-B signaling is sufficient to permit normal mammary gland development and ability to lactate in female Nse+Syn $d b / d b$ mice.

Examination of transgene expression by in situ hybridization revealed that complementation of expression may allow for normal leptin signaling in the hypothalamus as it relates to energy balance. The NSE-LEPR-B and SYN-LEPR-B transgenes together Bra Hth Liv KidPanc Int Mus Ing PG Ret BAT Tail Ctrl

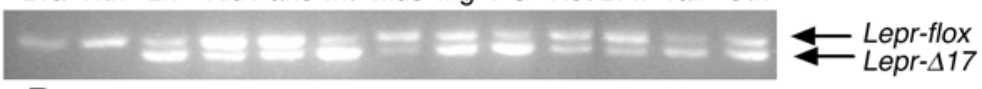

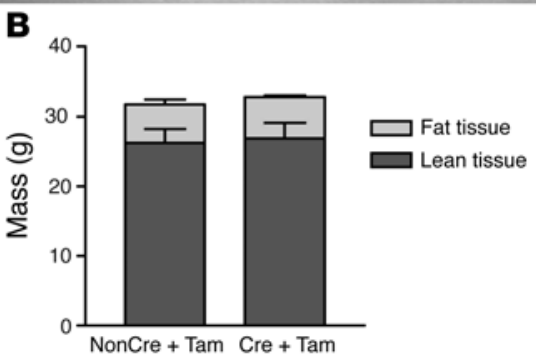

Figure 9

Deletion of peripheral signaling LEPR has no effect on adiposity. (A) Representative results of PCR-based genotyping of the Lepr locus in the tissues of male Cre+Tam mice. Four-month-old male Cre+Tam mice and nonCre+Tam controls were sacrificed 3 months after Tam treatment. PCR-based DNA analysis was used to determine the extent of the deletion of exon 17 (Lepr- $\Delta 17)$ in the brain (Bra), hypothalamus, liver, kidney (Kid), pancreas, small intestine (Int), skeletal muscle, inguinal fat (Ing), perigonadal fat (PG), retroperitoneal fat

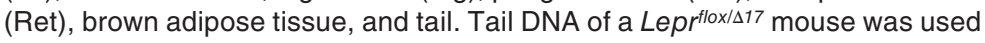
as a control (Ctrl). (B) Body compositions of 4-month-old male Cre+Tam mice $(n=7)$ and their nonCre+Tam controls $(n=5)$ were determined using DEXA 3 months after Tam treatment. 
provided relatively high levels of expression in all the relevant hypothalamic nuclei: PVN, arcuate nucleus (ARC), dorsomedial nucleus (DMN), VMN, ventral PMN, and the LH as well as the NTS and the area postrema in the hindbrain. In addition to these regions that are known to regulate energy homeostasis, we observed expression in regions of the brain not normally involved in energy homeostasis. This is a limitation of the approach we used. In this transgenic model, we cannot determine what contribution, if any, overexpression of LEPR-B and ectopic expression contributed to the phenotype of the transgenic $d b / d b$ mice. To address this issue, we conditionally deleted Lepr in peripheral tissues in order to produce a mouse with endogenous "brain-only" Lepr expression. Although the deletion was incomplete, the cell-autonomous function of LEPR would be expected to produce an effect on fat mass if leptin signaling was important in its regulation. However, the resulting mice with partial peripheral LEPR deficiency had normal body weight and body composition. As a whole, our data indicate that (a) restoration of leptin-receptor signaling in the brain can completely correct the obesity and diabetes of $d b / d b$ mice and (b) leptin signaling in peripheral tissues plays a minor role, if any, in normal energy homeostasis of these genetically manipulated mice. However, there is a possibility that direct leptin action on both the nervous system and peripheral organs is necessary for completely normal regulation of body composition, ingestive behavior, and reproduction. The current reductionist models do not address the potential for complexity and interactions (between various cell types throughout the body) that may be responsible for the phenotypic expression of complete loss of leptin signaling although extant genetically modified mouse models can be useful tools to examine these potential interactions.

\section{Methods}

Animals. Animals were housed in a barrier facility with a controlled ambient temperature of $22^{\circ} \mathrm{C}$ and a $14 / 10$-hour light-dark cycle. Animals were fed a standard laboratory chow diet (PicoLab Mouse Diet 20: 55\% carbohydrate, $20 \%$ protein, $9 \%$ fat; PMI Nutrition International) and sterilized water ad libitum. Pathogens were tested on a quarterly basis, and all serologies tested were negative throughout the study. Animals requiring anesthetization were given an i.p. injection of a ketamine/xylazine mixture $(50 \mathrm{mg} / \mathrm{kg}$ ketamine with $50 \mathrm{mg} / \mathrm{kg}$ xylazine). Animals were euthanized by carbon dioxide asphyxiation followed by cervical dislocation. Blood used for glucose determinations was collected in live, awake animals by nicked tail vein bleeding between 9:00 and 12:00 am EST. Fasted blood glucose measurements were performed between 9:00 and 12:00 am, following food removal and cage-bedding replacement at 4:00 pm the previous day. All procedures were approved by the Columbia University Institutional Animal Care and Use Committee.

Production of SYN-LEPR-B transgenic mice. A 4.3-kb SalI/XhoI fragment containing the Syn I promoter was inserted into the PacI site of a previously described plasmid containing rat growth hormone intron, full-length mouse LEPR-B, and simian virus 40 (SV40) late polyadenylation signal (10). The transgene was excised from the plasmid vector using SmaI/PmeI and purified as previously described (10). The generation of transgenic mice was performed as previously described (10). Seventeen progeny were obtained, 4 of which were positive for the transgene by PCR analysis of ear-clip DNA. Two male (nos. 1 and 17) C57BL/6JxCBA founders transmitted the transgene to their progeny when mated with mixed strain $\mathrm{C} 57 \mathrm{BL} /$ $6 \mathrm{JxFVB} / \mathrm{NJ} d b /+$ females. The expression of the transgene was evaluated in the progeny by nested $3^{\prime}$-RACE of LEPR-B mRNA to discern transgenic genomic cDNA from the reverse-transcribed cDNA from transgene mRNA.
The progeny of male no. 17 showed expression of the transgene in the brain and no detectable expression in nonneuronal tissues. The line derived from mouse no. 17 was used for further analysis. Syn $d b /+$ mice were backcrossed to $\mathrm{C} 57 \mathrm{BL} / 6 \mathrm{JxFVB} / \mathrm{NJ} d b /+$ mice and also intercrossed to sibling Syn $d b /+$ mice to produce progeny that were transgenic hemizygous, i.e., $S y n d b / d b$ and transgenic homozygous, i.e., Syn/Syn $d b / d b$ as well as $d b / d b, d b /+$, and $+/+$, to serve as littermate controls. N4 C57BL/6J Nse/Nse $d b / d b$ male mice, as previously described, were mated to $S y n d b /+$ females to produce compound hemizygous transgenic mice $N s e+S y n d b / d b$ (20). All mice used for this analysis were predominantly C57BL/6J mixed strain with contemporaneous littermates serving as controls.

The following PCR cycling parameters and primer combinations were used to genotype mice used in this study: SYN-LEPR-B transgene, GTGCTCCTGAGCCCCTTG and TCCCAGTGTAACAAAACCACA, 35 cycles of $94^{\circ} \mathrm{C}$ for 30 seconds, $55^{\circ} \mathrm{C} 30$ for seconds, and $72^{\circ} \mathrm{C}$ for 40 seconds, 368 bp product. Leprdb genotyping was performed as previously described (10).

Generation of a mouse model with deletion of peripheral signaling LEPR. Mice homozygous for a floxed Lepr allele were mated with mice expressing the Tam-inducible CRE-ER ${ }^{\mathrm{T} 2}$ fusion protein under the control of the ubiqui-

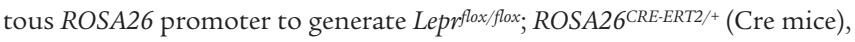
and Leprflox/flox littermates (nonCre mice) (16-19). The CRE-ER ${ }^{\mathrm{T} 2}$ knockin was a novel allele generated independently of the previous alleles, with the $\mathrm{ER}^{\mathrm{T} 2}$ domain perhaps providing a degree of central nervous system sparing that was not described for other CRE-ER ${ }^{\mathrm{T}}$ alleles. Deletion of exon 17 was induced by i.p. Tam at $1 \mathrm{mg} / \mathrm{d}$ for 5 days in 4-week-old male mice. Extent of deletion was assessed by PCR-based DNA analysis (33).

Nested 3'-RACE. Samples of hypothalamus, cerebral cortex, pituitary gland, liver, pancreas, skeletal muscle, white adipose, brown adipose, adrenal gland, ovary, and testes were dissected from each animal and placed in an RNA stabilization buffer (RNAlater, 1017980; QIAGEN). RNA was extracted using a guanidine thiocyanate method (RNeasy Mini Kit, 74104; QIAGEN). RNA was reverse transcribed using a commercially available kit (3'-RACE System, 18373-019; Invitrogen Corp.). The first PCR used the following gene-specific primer and cycling protocol: CAGGGCTGTATGTCATTG, an oligo d(T) adapter primer, and 1 cycle of $94^{\circ} \mathrm{C}$ for 3 minutes, 20 cycles of $94^{\circ} \mathrm{C}$ for 30 seconds, $57^{\circ} \mathrm{C}$ for 30 seconds, and $72^{\circ} \mathrm{C}$ for 1 minute 15 seconds. The second PCR used $2 \mu \mathrm{l}$ of product from the first PCR as template, and the following primer combination and PCR cycling protocol were used: TCCAAACCCCAAGAATTG, an oligo d(T) adapter primer, and 1 cycle of $94^{\circ} \mathrm{C}$ for 3 minutes, 35 cycles of $94^{\circ} \mathrm{C}$ for 30 seconds, $56^{\circ} \mathrm{C}$ for 30 seconds and $72^{\circ} \mathrm{C}$ for 1 minute 15 seconds. Hypoxanthine guanine phosphoribosyl transferase (Hprt) expression was used as a loading control. PCR amplification of Hprt used the following primer combination and cycling parameters: AGCAGTACAGCCCCAAAA and TTTGGCTTTTCCAGTTTCA, 35 cycles of $94^{\circ} \mathrm{C}$ for 30 seconds, $55^{\circ} \mathrm{C}$ for 30 seconds, and $72^{\circ} \mathrm{C}$ for 30 seconds.

Phenotypic analyses. Protocols for the following assays have been previously described: blood glucose, insulin, leptin, body composition by DEXA, naso-anal length measurements, food intake of individually housed mice, cold tolerance, and pancreatic islet histology. (20)

Assessment offertility. Five male Nse+Syn $d b / d b$ and 5 female Nse+Syn $d b / d b$ mice were individually mated at 6 weeks to female and male FVB/NJ mice, respectively. Females were monitored for resulting pregnancies. Litters were then monitored for survival to weaning age.

Quantification of neuropeptide gene expression. Hypothalamic RNA was isolated as described above. RNA was reverse transcribed using random hexamers and commercially available reverse transcriptase (SuperScript III First-Strand Synthesis System for RT-PCR, 18080-051; Invitrogen Corp.). Quantitative PCR was performed using a DyNAmo Hot Start SYBR Green qPCR kit (Finnzymes) with gene-specific primers. Amplification and fluorescence detection were 
performed on an Opticon2 (MJ Research; Bio-Rad). The PCR conditions were as follows: 40 cycles of $95^{\circ} \mathrm{C}$ for 10 seconds, $55^{\circ} \mathrm{C}$ for 10 seconds, and $72^{\circ} \mathrm{C}$ for 10 seconds. The forward and reverse primers for each amplicon were as follows: Agrp, GCATCAGAAGGCCTGACC and TCGCGGTTCTGTGGATCT; Pomc, GTGCCAGGACCTCACCAC and CTTCCGGGGGTTTTCAGT; Npy, ACTCCGCTCTGCGACACT and GTTCTGGGGGCGTTTTCT; Hprt, as described above. The data obtained were corrected for amplification efficiency and normalized to Hprt mRNA content (34).

LEPR-B in situ hybridization histochemistry. Free-floating in situ hybridization histochemistry (ISHH) was performed to demonstrate mouse LEPR-B mRNA levels in the brain of $+/+$, Syn $d b / d b, N s e+S y n d b / d b$, and Nse $d b / d b$ mice. The mouse LEPR-B probe was made using previously described methods (35). The ISHH procedure was a modification of methods described previously $(36,37)$. Brain sections were rinsed and stored in PBS-Azide, mounted on SuperFrost Plus slides (Fisher Scientific International), and exposed on BMR-2 film (Kodak) for 3 days. Slides were counterstained in thionin. Digital images were obtained on a Nikon Eclipse 400 microscope and a SPOT Insight digital camera (Diagnostic Instruments).

Statistics. HOMA was used to calculate relative insulin resistance $\left(\mathrm{G}_{0} \times \mathrm{I}_{0} / 22.5\right)$, where $\mathrm{I}_{0}$ is the fasting plasma insulin $(\mu \mathrm{U} / \mathrm{ml})$ and $\mathrm{G}_{0}$ is the fasting blood glucose (mmol/l). All statistical calculations were performed using GraphPad Prism version 3.02 for Windows (GraphPad Software). Two-tailed Student's $t$ test was performed when 2 groups were compared. When comparing more than 2 groups, 1-way ANOVA was used followed by Tukey's procedure to evaluate the significance of the differences between individual groups in such cases. A $P$ value of less than 0.05 was considered statistically significant. The results are reported as mean values \pm SEM.

\section{Acknowledgments}

This work was supported by NIH grants DK57621, DK26687, DK07647, DK56116, and DK53301.

Received for publication November 30, 2004, and accepted in revised form September 6, 2005.

Address correspondence to: Streamson C. Chua Jr., Departments of Medicine and Neuroscience, Albert Einstein College of Medicine, 1300 Morris Park Avenue, Belfer 701, New York, New York 10461, USA. Phone: (718) 430-2986; Fax: (212) 430-8557; E-mail: streamson@gmail.com.
1. Zhang, Y., et al. 1994. Positional cloning of the mouse obese gene and its human homologue. Nature. 372:425-432.

2. Frederich, R.C., et al. 1995. Leptin levels reflect body lipid content in mice: evidence for dietinduced resistance to leptin action. Nat. Med. 1:1311-1314.

3. Tartaglia, L.A. 1997. The leptin receptor. J. Biol. Chem. 272:6093-6096.

4. Chua, S.C., Jr., et al. 1996. Phenotypes of mouse diabetes and rat fatty due to mutations in the $\mathrm{OB}$ (leptin) receptor. Science. 271:994-996.

5. Chua, S.C., Jr. 1997. Monogenic models of obesity. Behav. Genet. 27:277-284.

6. Truett, G.E., Bahary, N., Friedman, J.M., and Leibel, R.L. 1991. Rat obesity gene fatty (fa) maps to chromosome 5: evidence for homology with the mouse gene diabetes (db). Proc. Natl. Acad. Sci. U. S. A. 88:7806-7809.

7. Chen, H., et al. 1996. Evidence that the diabetes gene encodes the leptin receptor: identification of a mutation in the leptin receptor gene in $\mathrm{db} / \mathrm{db}$ mice. Cell. 84:491-495.

8. Bates, S.H., and Myers, M.G., Jr. 2003. The role of leptin receptor signaling in feeding and neuroendocrine function. Trends Endocrinol. Metab. 14:447-452.

9. Sakimura, K., et al. 1995. Upstream and intron regulatory regions for expression of the rat neuron-specific enolase gene. Brain Res. Mol. Brain Res. 28:19-28.

10. Kowalski, T.J., Liu, S.-M., Leibel, R.L., and Chua, S.C., Jr. 2001. Transgenic complementation of leptin-receptor deficiency. I. Rescue of the obesity/ diabetes phenotype of LEPR-null mice expressing a LEPR-B transgene. Diabetes. 50:425-435.

11. Bjorbaek, C., and Kahn, B.B. 2004. Leptin signaling in the central nervous system and the periphery. Recent Prog. Horm. Res. 59:305-331.

12. Huan, J.N., et al. 2003. Adipocyte-selective reduction of the leptin receptors induced by antisense RNA leads to increased adiposity, dyslipidemia, and insulin resistance. J. Biol. Chem. 278:45638-45650.

13. Galvin-Parton, P.A., Chen, X., Moxham, C.M., and Malbon, C.C. 1997. Induction of Galpha q-specific antisense RNA in vivo causes increased body mass and hyperadiposity. J. Biol. Chem. 272:4335-4341.
14. Schoch, S., Cibelli, G., and Thiel, G. 1996. Neuronspecific gene expression of synapsin I. J. Biol. Chem. 271:3317-3323.

15. Hoesche, C., Sauerwald, A., Veh, R., Krippl, B., and Kilimann, M. 1993. The 5'-flanking region of the rat synapsin I gene directs neuron-specific and developmentally regulated reporter gene expression in transgenic mice. J. Biol. Chem. 268:26494-26502.

16. Balthasar, N., et al. 2004. Leptin receptor signaling in POMC neurons is required for normal body weight homeostasis. Neuron. 42:983-991.

17. Feil, R., Wagner, J., Metzger, D., and Chambon, P. 1997. Regulation of Cre recombinase activity by mutated estrogen receptor ligand-binding domains. Biochem. Biophys. Res. Commun. 237:752-757.

18. Indra, A.K., et al. 1999. Temporally-controlled sitespecific mutagenesis in the basal layer of the epidermis: comparison of the recombinase activity of the tamoxifen-inducible Cre-ER(T) and Cre-ER(T2) recombinases. Nucleic Acids Res. 27:4324-4327.

19. Vooijs, M., Jonkers, J., and Berns, A. 2001. A highly efficient ligand-regulated Cre recombinase mouse line shows that LoxP recombination is position dependent. EMBO Rep. 2:292-297.

20. Chua, S.C., Jr., et al. 2004. Transgenic complementation of leptin receptor deficiency. II. Increased leptin receptor transgene dose effects on obesity/ diabetes and fertility/lactation in lepr-db/db mice. Am. J. Physiol. Endocrinol. Metab. 286:E384-E392.

21. Grill, H.J., et al. 2002. Evidence that the caudal brainstem is a target for the inhibitory effect of leptin on food intake. Endocrinology. 143:239-246.

22. Buyse, M., et al. 2001. Expression and regulation of leptin receptor proteins in afferent and efferent neurons of the vagus nerve. Eur. J. Neurosci. 14:64-72.

23. Fan, W., et al. 2000. The central melanocortin system can directly regulate serum insulin levels. Endocrinology. 141:3072-3079.

24. Saper, C.B., Chou, T.C., and Elmquist, J.K. 2002. The need to feed: homeostatic and hedonic control of eating. Neuron. 36:199-211.

25. Huo, L., Munzberg, H., Nillni, E.A., and Bjorbaek, C. 2004. Role of signal transducer and activator of transcription 3 in regulation of hypothalamic trh gene expression by leptin. Endocrinology. 145:2516-2523.
26. Beltramino, C., and Taleisnik, S. 1985 . Ventral premammillary nuclei mediate pheromonal-induced LH release stimuli in the rat. Neuroendocrinology. 41:119-124.

27. Elias, C.F., et al. 2001. Characterization of CART neurons in the rat and human hypothalamus. J. Comp. Neurol. 432:1-19.

28. Rondini, T.A., Baddini, S.P., Sousa, L.F., Bittencourt, J.C., and Elias, C.F. 2004. Hypothalamic cocaine- and amphetamine-regulated transcript neurons project to areas expressing gonadotropin releasing hormone immunoreactivity and to the anteroventral periventricular nucleus in male and female rats. Neuroscience. 125:735-748.

29. Yokosuka, M., et al. 1999. Female-soiled bedding induced fos immunoreactivity in the ventral part of the premammillary nucleus (PMv) of the male mouse. Physiol. Behav. 68:257-261.

30. Bates, S.H., et al. 2003. STAT3 signalling is required for leptin regulation of energy balance but not reproduction. Nature. 421:856-859.

31. Sainsbury, A., et al. 2002. Y4 receptor knockout rescues fertility in ob/ob mice. Genes Dev. 16:1077-1088.

32. Malik, N.M., et al. 2001. Leptin requirement for conception, implantation, and gestation in the mouse. Endocrinology. 142:5198-5202.

33. McMinn, J.E., et al. 2004. An allelic series for the leptin receptor gene generated by CRE and FLP recombinase. Mamm. Genome. 15:677-685.

34. Liu, W., and Saint, D.A. 2002. Validation of a quantitative method for real time PCR kinetics. Biochem. Biophys. Res. Commun. 294:347-353.

35. Elmquist, J.K., Bjorbaek, C., Ahima, R.S., Flier, J.S., and Saper, C.B. 1998. Distributions of leptin receptor mRNA isoforms in the rat brain. J. Comp. Neurol. 395:535-547.

36. Elias, C.F., et al. 1998. Chemically defined projections linking the mediobasal hypothalamus and the lateral hypothalamic area. J. Comp. Neurol. 402:442-459.

37. Yamamoto, H., et al. 2003. Glucagon-like peptide-1responsive catecholamine neurons in the area postrema link peripheral glucagon-like peptide-1 with central autonomic control sites. J. Neurosci. 23:2939-2946. 